\title{
ACCESO AL EMPLEO DE LAS PERSONAS CON DISCAPACIDAD: SITUACIÓN EN EL EMPLEO EN LAS PERSONAS CON ENFERMEDAD MENTAL
}

Manuel Francisco Salinas Tomás

Departamento de Trabajo Social y Servicios Sociales

Facultad de Ciencias Sociales - Universitat de València

\section{Fernando Marhuenda Fluixá}

Vicedecano de Relaciones Internacionales y Cultura

Departamento de Didáctica y Organización Escolar

Facultad de Filosofía y Ciencias de la Educació - Universitat de València

\section{RESUMEN}

Las personas con enfermedad mental encuentran mayores dificultades en el acceso al empleo que otras personas que también forman parte del colectivo de personas con discapacidad. Los datos estadísticos que hablan del empleo de personas con discapacidad suelen aglutinar bajo el término discapacidad psíquica tanto a personas con enfermedad mental como a personas con discapacidad intelectual. Dicha agrupación da lugar a equívocos, puesto que se trata de discapacidades bien diferenciadas y cuyo tratamiento requiere un abordaje específico tanto en apoyos como en medidas específicas de inserción.

Un estudio de los datos estadísticos de las diferentes modalidades de inclusión laboral reguladas en la legislación nos lleva a la conclusión de que es necesario un cambio en el sistema de recogida de datos y su tratamiento para poder diferenciar la enfermedad mental del resto y así poder elaborar medidas de inclusión diferenciadas y por tanto de mayor eficacia.

PALABRAS CLAVE: Discapacidad, empleo, inclusión, enfermedad mental, LGD, LISMI.

CLAVES ECONLIT: A13, B55, D63, J79, L39.

Cómo citar este artículo/How to cite this article: SALINAS TOMÁS, M.F., \& MARHUENDA FLUIXÁ, F.: “Acceso al empleo de las personas con discapacidad: situación en el empleo en las personas con enfermedad mental", CIRIEC-España, Revista Jurídica de Economía Social y Cooperativa, n³ 36, 2020, pp. 273-311. DOI: 10.7203/CIRIEC-JUR.36.16980. 


\section{ACCESS TO EMPLOYMENT FOR PEOPLE WITH DISABILITIES: PEOPLE WITH MENTAL ILLNESS BEFORE EMPLOYMENT}

\section{EXPANDED ABSTRACT}

Preparation and access to the labour market of people with disabilities has improved along the past four decades as a result of the demand of civil society, families and people with disabilities themselves. However, little is known about the particular difficulties that people with mental illness face when trying to access an employment and try to keep it, their employability being often disregarded to the point that they sometimes hide their disability to their employers and colleagues in order to be able to enter employment.

This paper attempts to cover the specific obstacles that people with mental illness have to address and to discuss whether or not they find the support of specific measures that take into account their particular needs. In order to accomplish our aim, we structure the paper in three sections: in the first one, we review the sources of information available in Spain and we assess the possibilities we find in them for our purpose, on the one hand; and the limitations that these sources entail and that will affect our work on the other hand.

The second section focuses upon the different legislative measures that have been conceived, planned and developed along the years. In doing so, we follow the same order of the measures that were initially stablished by the LISMI, the Law passed in 1982 that was a landmark in the understanding of disability and handicap in the country and that has been the framework valid to structure any new development along the past four decades in terms of educational, social and economic inclusion of people with disabilities. This section is divided in two subsections, one on ordinary employment and a second one on protected employment.

Each subsection covers the different measures that have a legal reference, namely: the reserve quote of $2 \%$ for companies that employ more than 50 workers; access to public employment for people with disabilities; self-employment of people with disabilities; supported employment programs, labour or work-enclaves, and special employment centers. The structure of the different subsections is similar: a normative definition of the measure, an analysis of the available data and finally, a subsection on what is the situation of the measure regarding its impact upon people with mental illness and what could be done to improve its effectiveness. The third and final section discusses the implications of our findings, while also draws attention to the need of more precise, stable and sustainable sets of data that allow researchers but also policy-makers and employers and unions to plan proper measures to facilitate the integration of people with mental illness in the labour market. 
In section one we portray the two main sources of information, consisting of the Olivenza Report (the 2019 version is the latest one) and the National Institute of Statistics reports (we have used data from 2019) as well as the Observatory of Employment and Disability (also data from 2019). These being the main sources of data in the country, the problem we have found is the difficulty to identify mental illness as a particular kind of disability, often mixed, mingled or dissolved in other disability types, which leads to confusion and lack of precision, as mental illness is considered as intellectual disability, which it is clearly not. Therefore, in 2019 we have found very similar problems to those already pointed to by the Olivenza report on the situation of disability in Spain in 2019, indicating three obstacles we have also faced: lack of sources; methodological differences used to measure disability as well as the variability in frequency and sequence to obtain the data, something that is not amended whenever the date are claimed and updated.

The second section of the article starts with a general overview on the main laws ruling the object of our paper, the LISMI in 1982 and the General Law on Disability approved in 2013; consisting of an update of the previous with the relevant change of focus from the difficulties and limitations into the capacities and possibilities, therefore with a much more modern approach and one according to current scientific developments and social demands as well.

A review of the different legislative measure follows that introduction, starting with the reserve quote of the $2 \%$ in companies hiring more than 50 workers, this being one of the most inclusive measures insofar it consists of employing someone in the ordinary labour market. The legislation covering this quote is explained, and we specify what are the rules behind the calculation of the quote and what percentage of disability is needed to apply for the reserve quote. The paper also presents how can this reserve quote be avoided, an exception in the legislation that yields way to several of the other measures, most of which are not as inclusive as the reserve quote should be. The second measure reviewed in the paper is access to public employment, which consists of a particular application of the reserve quote in the case of the public administrations (national, regional and local) and that has proved useful yet with two necessary considerations: the impact of the 2008 financial crisis upon public employment due to the austerity measures applied by the European Union has been a considerable reduction of jobs available in the public sector, the second amendment related to the level of qualification that the public administration reserves for people with disability, which often leads to low qualified positions and therefore has an impact upon differential access to public employment. Like in the previous case, the lack of proper data invites us to suggest hypothesis on how the measure benefits or not people with mental illness specifically. The third measure we consider is that of self-employment which, to our surprise, despite added difficulties one may consider for people with disabilities has reached a larger percentage than that of the public administration. However, these data must be read with caution, as 
the coverage of self-employment is strongly related to the type of disability and this implies that people with mental illness are often out of this equation. Fourth we address supported employment, ruled in Spain in 2007 and which consists of an adaptation of a position in the ordinary labour market through staff trained to develop the necessary adaptation. This section shows the difficulties that people with mental illness face in entering the ordinary labour market without proper support, whilst this is often provided as if they were people with intellectual disabilities. We move then onto supported employment. The first subsection covers the 'jewel of the crown' among all measures, special employment centers, those employing by large most of the people with disabilities (and people with mental illness among them) even if they have become in fact a segregated labour market and therefore the least inclusive among the different measures. Then we move into labour enclaves, which are a measure so complex in bureaucratic terms that few companies opt for it. We finish the paper claiming for better and more precise data in order to make visible mental illness, to address it differently to intellectual disability, in order to be precise in policy planning and in providing appropriate support measures.

KEYWORDS: Disability, employment, inclusion, mental illness, general dependency law, social integration of handicapped people law. 


\section{SUMARIO}

1. Introducción. 1.1. Fuentes de información y bases de datos consultadas. 1.2. Datos generales sobre la discapacidad en España. 2. El empleo de las personas con discapacidad. Modalidades e incidencia en las personas con enfermedad mental. 2.1. El empleo ordinario para personas con con discapacidad. 2.2. El empleo protegido. 3. Recapitulación. Bibliografía. Normativa.

\section{Introducción}

En la sociedad y cultura occidentales, la condición de ciudadanía para la mayoría de las personas viene dada principalmente por el acceso al mercado laboral a través del empleo. Es obvio pensar que también lo va a ser para cualquier persona con discapacidad.

El empleo normaliza y confiere autonomía a la persona, en tanto en cuanto le dota de medios económicos para al menos subsistir e independizarse. Así, una de las vías que ha permitido a las personas con discapacidad comenzar a salir de la exclusión ha sido la de su incorporación al mercado laboral. La inclusión laboral depende de las aptitudes para trabajar, de las capacidades de la persona, y ahí es donde la sociedad traza una línea divisoria que suele dejar fuera a las personas con discapacidad.

Siendo el empleo en la empresa ordinaria la situación ideal de integración laboral de la persona con discapacidad, tanto su escasez junto a la mirada tradicional de la persona con discapacidad como "no capaz", llevan a los poderes públicos a convertirse en los garantes del derecho universal al trabajo, tanto más de las personas que se encuentran en situación de desventaja como es el caso de las personas con discapacidad. Cada Estado, en su función protectora del derecho de la persona con discapacidad, establece una serie de medidas que tienen la intención de garantizar que la persona pueda desarrollarse con plenitud.

Sin embargo, a nivel internacional la cuestión es plural. Cuando nos referimos a personas con discapacidad en relación al empleo protegido, la mirada y perspectiva desde la que se enfoca es diversa, abarcando desde una concepción de "paciente" basada en una sobreprotección, pasando por "personas en procesos de formación", hasta la consideración de "trabajadores" (Migliore, 2010).

Portero y Aneiros (2008) realizan un análisis sobre el recorrido de las políticas sobre discapacidad que abarca desde unos inicios de corte paternalista, con acciones 
aisladas y centradas en cubrir la incapacidad de las personas a través de medidas asistenciales. Más adelante, en la década de los 80 , se pasa a un enfoque de derechos basado en las dificultades de integración de las personas con discapacidad incluyendo la existencia de "factores sociales de exclusión y por último, en los años 90 se pone la mirada en la igualdad de oportunidades y comienzan a desarrollarse políticas que favorezcan la participación plena del colectivo a través de la acciones transversales ${ }^{1}$. Hoy en día existen medidas y modalidades como el empleo con apoyo, las empresas de inserción, los enclaves laborales, los centros especiales de empleo; así como distintas cuotas de contratación en función del tamaño de la empresa. Sin embargo, el deterioro de la calidad del empleo y de las relaciones laborales, en especial tras la crisis financiera de 2008, dificultan la inserción laboral de personas y colectivos con discapacidad.

En este sentido, Rodríguez y Cueto (2013) señalan que, pese a que actualmente la inclusión laboral es uno de los factores clave para que la persona con discapacidad pueda desarrollarse plenamente alcanzando su independencia personal y económica, no siempre ha sido así. Ha habido una evolución de políticas desde la búsqueda de garantía de ingresos a otras centradas en el empleo como principal herramienta de inclusión, en el valor del trabajo, tanto intrínseco como instrumental, como eje de normalización de la vida, así como en la concepción de las personas con discapacidad como capaces de trabajar y por lo tanto de contribuir también a fortalecer el Estado de Bienestar.

La legislación española plantea un sistema de protección en materia de empleo de la persona con discapacidad, que se plasman en una serie de medidas que van a favorecer la inclusión laboral de la misma. Las diferentes modalidades de empleo para personas con discapacidad tienen como objetivo el ser medidas que ayuden a salvar las barreras con que la persona se va a encontrar a la hora de acceder al empleo, más si cabe en un mercado de trabajo segmentado y dualizado. De la misma manera que la discapacidad es un hecho heterogéneo, las medidas inclusivas también han de serlo.

\subsection{Fuentes de información y bases de datos consultadas}

$\mathrm{Al}$ realizar un análisis de la situación de las personas con enfermedad mental en relación al empleo, la principal dificultad que encontramos consiste en que la mayoría de las bases de datos disponibles que hablan de empleo y discapacidad unen en el mismo subgrupo de discapacidad denominado psíquicas (salvo las del INE y solo

1. En lugar de centrar el esfuerzo en políticas concretas de integración, se busca que todas las acciones y políticas generales incluyan ese enfoque de participación plena. 
haciendo referencia a datos globales sobre tasas de actividad, paro y empleo), a las personas con enfermedad mental ${ }^{2}$ y a las personas con discapacidad intelectual ${ }^{3}$. En este sentido, una revisión del Informe Olivenza 2019, el informe ODISMET 2019 o el último informe del IMSERSO (31/12/2017), confirman este hecho. Consideramos este aspecto muy relevante, puesto que las problemáticas y necesidades, también de apoyo laboral, van a ser diferentes y, sin embargo, en términos generales son tratadas como si no lo fueran.

La información de las bases de datos utilizadas en esta investigación corresponde a las fuentes oficiales de mayor fiabilidad a las que podemos acceder y que aparecen detalladas más abajo. Aun así, conviene tomar los datos como aproximativos y con amplio margen de error debido a las diferentes metodologías empleadas para su obtención según cada una de las fuentes, así como las diferencias en el periodo de obtención de los datos.

Para la recopilación de los datos que analizaremos en el artículo, hemos recurrido a diversas fuentes que coinciden en mostrar la dificultad de acceder a datos exactos y coincidentes. La escasez de datos estadísticos actualizados junto a la disparidad de indicadores utilizados en el análisis de los muestreos nos lleva a tomar los mismos con ciertas reservas pues el margen de error es claramente observable cuando el nivel de desagregación buscado es mayor. Tres son las fuentes principales disponibles:

- El propio Informe Olivenza 2019 (Jiménez, 2019).

- Base de datos del INE ${ }^{4}$. SEPE. Informe sobre el empleo de las personas con discapacidad (Serie 2014-2018) publicado en diciembre de 2019. (Observatorio de las Ocupaciones, 2019).

- ODISMET. Informe 4 del Observatorio sobre Discapacidad y Mercado de Trabajo (2019).

- IMSERSO. Base estatal de datos de personas con valoración del grado de discapacidad (Datos a 31/12/2017).

2. Nos referiremos a las personas con enfermedad mental en relación al empleo, a aquellos que tengan reconocido un grado de discapacidad de al menos el $33 \%$ fruto de su enfermedad.

3. Mientras que en las personas con discapacidad intelectual la etiología es fruto de algún síndrome o situación sobrevenida en el embarazo o parto y suele ir acompańado de dificultades en el aprendizaje y retraso mental (por ejemplo, las personas con síndrome de Down), las personas con enfermedad mental son personas cuya discapacidad es fruto de una enfermedad cursada por lo general a partir de la adolescencia y que no tiene porque ir acompañada de retraso mental (trastornos psicóticos, esquizofrenia, etc.).

4. INE Instituto Nacional de Estadística. 
El Informe Olivenza 20195, sobre "la situación general de la discapacidad en España", ya señala que la dificultad de las fuentes de información a la hora de abordar la discapacidad desde una perspectiva estadística implica asumir cuatro obstáculos: a la escasez de fuentes hay que unir las diferencias metodológicas en la medición de la discapacidad, la variabilidad en las cadencias de actualización de datos y la segmentación territorial. Así sucede también en nuestro trabajo.

\subsection{Datos generales sobre la discapacidad en España}

Analizar cualquier dato sobre personas con discapacidad en España, supone asumir unos márgenes de error amplios debido a la complejidad y variabilidad de los diferentes indicadores utilizados en las distintas bases de información. En los últimos años, la posibilidad de cruzar datos de distintas instituciones y organismos ha supuesto, en algunos aspectos, poder acceder a información más detallada y concreta, a la vez que ha puesto de manifiesto la dificultad de utilizarlos como datos objetivables, más allá de un acercamiento relativo. Aspectos como la inclusión de las personas con dependencia reconocida como personas con discapacidad, bases de datos inexactas, que cruzan datos actuales con los tomados hace unos ańos, la coexistencia de diferentes tipologías de discapacidad en la misma persona. Confieren a los resultados estadísticos márgenes de error significativos, fruto del cruce de datos en ocasiones imposibles.

Así, un primer acercamiento a la población con discapacidad en España refleja que, en datos unificados de 2017, existía censada una población de 46.658 .447 personas, de las que 3.177.531 tenían algún tipo de discapacidad. Estos datos reflejan que la población con discapacidad supone aproximadamente un 6\% de la total, como reflejamos en la tabla 1 .

5. Es necesario señalar que las encuestas realizadas en España con un análisis más profundo y detallado son la Encuesta de Deficiencias, Discapacidades y Minusvalías de 1986, la Encuesta de Discapacidades, Deficiencias y Estado de Salud de 1999 y la Encuesta de Discapacidad, Autonomía personal y situaciones de Dependencia de 2008. Pese a que los datos que aparecen en las mismas no van a ser utilizados en esta investigación, sí que es necesario nombrar que los diferentes informes sobre la situación de las personas con discapacidad, inclusos los más actuales, hacen referencia a las mismas por ser, en algunos casos, los únicos datos obtenidos a través de encuestas en un momento dado. Este es el caso del informe Olivenza 2016 sobre la situación de la discapacidad en España. 


\section{Tabla 1.}

Comparativa de personas con y sin discapacidad en Espańa, en edad laboral (16 a 64 años) y en situación de empleo

\begin{tabular}{|l|r|r|r|r|r|}
\hline & \multicolumn{1}{|c|}{ Espańa } & $\begin{array}{c}\text { Población en } \\
\text { edad laboral }\end{array}$ & $\begin{array}{c}\text { \% en edad } \\
\text { laboral }\end{array}$ & $\begin{array}{c}\text { Afiliación } \\
\text { a la SS. }\end{array}$ & $\begin{array}{c}\text { \% en } \\
\text { empleo }\end{array}$ \\
\hline Personas sin discapacidad & 43.480 .916 & 30.050 .400 & $69,11 \%$ & 19.560 .000 & $65,01 \%$ \\
\hline Personas con discapacidad & 3.177 .531 & 1.860 .600 & $58,55 \%$ & 269.736 & $14,49 \%$ \\
\hline Población total & 46.658 .447 & 31.911 .000 & $68,39 \%$ & 19.073 .067 & $59,77 \%$ \\
\hline
\end{tabular}

Fuente: Elaboración propia sobre datos del Imserso (2017), Base estatal de datos de personas con valoración del grado de discapacidad, del INE 2017 y del informe 4 del Observatorio sobre Discapacidad y Mercado de Trabajo ODISMET (2019) ${ }^{6}$.

$\mathrm{Al}$ centramos en la población activa (entre 16 y 64 años), observamos que de un total de 30.050.400 personas, 1.860 .600 lo serían con discapacidad reconocida o asimilada ${ }^{7}$. Además, solamente 1.335.100, tiene la condición reconocida de discapacidad que las acredita para poder tener un contrato específico para personas con discapacidad, estando además registradas en la $\mathrm{BEPD}^{8}$. Este dato es significativo pues supone un diferencial del 1,4\% (525.500). Esta variación se debe a que el INE incluye en la encuesta sobre el empleo de las personas con discapacidad, además de las registradas en la BEPD, datos sobre medidas de fomento de empleo de la Tesorería General de la Seguridad Social, prestaciones procedentes del Registro de Prestaciones Sociales Públicas del INSS y datos sobre personas en situación de dependencia extraídos del SAAD ${ }^{9}$. Además, desde 2014, al amparo de lo previsto en el art. 4.2 del Real Decreto Legislativo 1/2013, también se suman pensionistas de clases pasivas, así como pensionistas de la seguridad social con una incapacidad permanente, total, absoluta o gran invalidez; si bien es importante destacar que este aspecto ha sido cuestionado en 2018 por dos sentencias posteriores en las que el Pleno de la Sala IV del TS concluye que no puede reconocerse de manera automática y a todos los efectos un grado de discapacidad del $33 \%$ a los pensionistas de incapacidad total, absoluta o gran invalidez.

6. El Informe 4 del Observatorio sobre Discapacidad y Mercado de Trabajo ODISMET (2019) recoge datos de la encuesta del INE 2019 sobre situación de las personas con discapacidad en relación al empleo.

7. El INE señala que, desde 2014, se consideran personas asimiladas a la condición de discapacidad aquellas que reciban una prestación del INSS teniendo reconocidas una situación de dependencia.

8. Base Estatal de datos de personas con discapacidad.

9. Sistema de Autonomía y Atención a la Dependencia. 
En relación a las personas con enfermedad mental y el empleo, una revisión de los informes y bases de datos con las que trabajamos en el presente artículo muestra una serie de datos desagregados en unos casos y en otros no para referirse a las personas con enfermedad mental, a saber:

El Informe del Mercado de Trabajo de las Personas con Discapacidad del Observatorio de las Ocupaciones, elaborado por el Observatorio de las Ocupaciones del SEPE a partir de los datos del SISPE ${ }^{10}$ correspondientes al año 2018, al señalar el volumen de contrataciones, habla de personas con discapacidad psíquica englobando a las personas con discapacidad intelectual y a las personas con enfermedad mental.

El informe del INE 2018 sobre el Empleo de las Personas con Discapacidad sí que discrimina entre personas con discapacidad intelectual y personas con enfermedad mental al referirse a las tasas de actividad y empleo; si bien no incluye información sobre las contrataciones.

Los sucesivos informes elaborados por el Observatorio sobre la Discapacidad y Mercado de Trabajo (ODISMET), muestran información diferente. Así al hablar de las tasas de actividad y empleo, sí que distingue entre personas con discapacidad intelectual y personas con enfermedad mental ${ }^{11}$, mientras que al referirse a las contrataciones, habla de psíquicas, sin diferenciar ambos subgrupos ${ }^{12}$.

El informe Olivenza 2019, al igual que los anteriores, utiliza datos del Observatorio sobre la Discapacidad y Mercado de Trabajo, por lo que las diferencias de nomenclatura entre las tablas referidas a las tasas de actividad y empleo, también son diferentes a las de contratación.

En este artículo, elegimos omitir el sesgo de género debido a que las cifras y datos que vamos a utilizar en algunos casos o bien no aparece o bien no aporta elementos significativos, suponiendo sin embargo acrecentar la complejidad del análisis ${ }^{13}$. Sin embargo, no queremos dejar de nombrar algunos datos básicos en relación a este tema: una apreciación necesaria es la de comprobar que mientras que hablamos de cifras totales de personas con discapacidad frente a las personas con discapacidad

10. Sistema de Información de los Servicios Públicos de Empleo.

11. Hasta el informe 4, utiliza el término "mental" para referirse a personas con enfermedad mental, mientras que en el último, informe 5, utiliza la nomenclatura "psicosocial" para referirse al mismo subgrupo de discapacidades.

12. Esto es así, debido a que para elaborar las tablas de datos sobre las tasas de actividad y empleo utiliza las bases de datos del INE, mientras que para las de contrataciones utiliza las del SEPE.

13. Si bien en esta ocasión elegimos omitir el sesgo de género, sí que sería interesante y necesario el poder realizar el poder realizar este análisis teniéndolo en cuenta pues mostraría seguro datos relevantes en relación a la brecha que sufre la mujer con discapacidad. 
en edad activa. Otra diferencia apreciable en cuanto a distribución por sexo es la de que, cuando hablamos de cifras totales, el porcentaje de mujeres con discapacidad es mayor que el de hombres (un 50,9\% frente al 49,1\%). Cuando nos referimos a la población activa con discapacidad, comprendida entre los 16 y los 64 ańos, nos encontramos con una inversión del porcentaje de hombres $(57,7 \%)$ con respecto a mujeres $(43,3 \%)$ con discapacidad entre 16 y 64 años.

Las causas principales de este hecho significativo son las siguientes: Cuando hablamos del total de personas con discapacidad, las estadísticas siguen el mismo patrón que con el del resto de la población, hay más mujeres que hombres, principalmente porque el promedio de vida de la mujer con respecto al hombre es mayor. Sin embargo, la inversión de porcentajes en la población activa con discapacidad es debida principalmente a que un porcentaje significativo de personas con discapacidad son fruto de accidentes laborales en puestos de trabajo de riesgo que tradicionalmente han ocupado -y lo siguen haciendo- hombres. Sin duda, la brecha género en el empleo con discapacidad también es considerable.

\section{El empleo de las personas con discapacidad. Modalidades e incidencia en las personas con enfermedad mental}

En España, la Ley de Integración Social de los Minusválidos de 1982 (LISMI) ${ }^{14}$ supone el momento clave en el que, por primera vez, se articula un texto que, unido al posterior desarrollo de la misma y su reglamentación y más adelante revisado y actualizado a través de la Ley General de Discapacidad (en adelante LGD), aprobada mediante el RD Legislativo $1 / 2013^{15}$, va a plantear un nuevo paradigma de la discapacidad poniendo el acento en las capacidades más que en las limitaciones.

14. LISMI. Ley 13/1982, de 7 de abril. Ley de Integración Social de los Minusválidos. Si bien es cierto que la LISMI es el primer referente claro y específico vertebrador de la discapacidad, podemos encontrarnos con la existencia de normativa dispersa y puntual entre la que destaca la Ley 51/1980, de 8 de octubre, Ley Básica del Empleo, que puede ser germen de la ley posterior -LISMI- al citar en su art. 13 que «(...) con el objeto de facilitar el empleo a personas cuyas deficiencias les imposibilite emplearse en empresas normales, el Gobierno dictará normas para fomentar el trabajo en centros especiales de empleo».

15. La Ley General de derechos de las personas con discapacidad y de su inclusión social, aprobada mediante el Real Decreto Legislativo 1/2013, de 29 de noviembre, ha integrado en una sola norma la Ley de Integración Social de Personas con Discapacidad (LISMI), de 1982; la Ley de Igualdad de Oportunidades, no Discriminación y Accesibilidad Universal de las Personas con Discapacidad, de 2003, y la Ley por la que se establece el régimen de infracciones y sanciones en materia de igualdad de oportunidades, no discriminación y accesibilidad universal de las personas con discapacidad, de 2007. 
La LISMI, en su artículo 3, ya hace referencia a que los poderes públicos deberán prestar los recursos necesarios para favorecer el derecho de la integración laboral de las personas con discapacidad y en su Capítulo VII (artículos 37 a 48) titulado "de la integración laboral" cita las primeras medidas promulgadas, para favorecer el acceso al empleo público y privado, al autoempleo (art. 38) y al desarrollo del empleo protegido a través de los Centros Especiales de Empleo, en adelante CEE (art. 41 a 46).

El desarrollo e impulso real de las medidas de integración viene a darse a finales de la década de los 90 y principios de siglo. Primero los CEE (LEY 13/1982) y más adelante los enclaves laborales (RD 27/2000) y los programas de empleo con apoyo (RD 870/2007). De entre todas estas medidas, los CEE son los primeros en ponerse en marcha, generando un incremento importante de inclusión laboral hasta la llegada de la crisis financiera de 2008. En ese momento, pese a sufrir un proceso de desaceleración en su crecimiento, destacan como una de las medidas de integración que mejor resiste a los embates de la crisis. Rodríguez y Cueto (2013) concluyen que, en tanto que los contratos en empleo ordinario han sufrido un importante descenso, la contratación en CEE desde el año 2006 se ha duplicado; si bien el incremento principal ha sido en contratos temporales, con la precarización que ello conlleva. No obstante, también es cierto que, en este escenario de crisis, los CEE desempeñan un "refugio de empleo" para las personas con discapacidad.

A continuación, profundizaremos en algunos datos básicos del impacto de las diferentes medidas de inclusión laboral de personas con discapacidad en general así como, en particular, en personas con enfermedad mental, considerando la legislación en la que se amparan y proponiendo posibles indicaciones que pudieran contribuir a subsanar la problemática de las personas con enfermedad mental en relación al empleo.

Distinguiremos a continuación entre modalidades de empleo (para referirnos al empleo ordinario público y privado, el autoempleo y el empleo protegido/CEEs), las medidas específicas para el acceso a estas modalidades (enclave laboral, cuota del 2\% y cuotas en el empleo público) y las metodologías de apoyo (como el empleo con apoyo para el acceso y tránsito al empleo ordinario).

\subsection{El empleo ordinario para personas con discapacidad}

Siempre que sea posible, la persona con discapacidad debería de poder participar de la actividad laboral en un entorno de trabajo ordinario o normalizado, ya sea una empresa pública o privada y en el que la mayoría de trabajadores esté compuesta de personas sin discapacidad. 
Acceso al empleo de las personas con discapacidad: situación en el empleo en las personas...

(pp. 273-311)

El empleo ordinario es aquel prestado por un trabajador con discapacidad en empresas normalizadas, regulado por el régimen laboral común. Previsto en el articulo 37.2.a) de la LGPD, se caracteriza por la adopción por los poderes públicos de una serie de medidas de acción positiva tendentes a fomentar la contratación del trabajador con discapacidad y a procurar su integración en el mercado ordinario de trabajo, garantizando de esta manera el principio de igualdad de oportunidades. Las medidas establecidas han sido las siguientes: el fomento del empleo, la adaptación de puesto de trabajo y/o dotación de medios de protección personal, la cuota de reserva de puestos de trabajo para personas con discapacidad, el empleo con apoyo, así como las especialidades en los contratos en prácticas y para la formación, previstos en el Estatuto de los Trabajadores.

García (2017:63)

El Real Decreto 364/2005, de 8 de abril regula, de una manera específica, el cumplimiento alternativo con carácter excepcional de la cuota de reserva en favor de los trabajadores con discapacidad.

Entre las medidas que nos vamos a encontrar en este ámbito se encuentran las siguientes ${ }^{16}$ :

1. La cuota de reserva de puestos de trabajo en empresas de más de 50 trabajadores del $2 \%$ para las personas con discapacidad y los incentivos económicos a la contratación.

La cuota de reserva significa que las empresas con 50 o más trabajadores han de reservar el 2 por 100 de los puestos de trabajo para las personas con discapacidad y se establece en la Ley General de derechos de las personas con discapacidad y de su inclusión social. El cumplimiento de la cuota de reserva se puede sustituir por acciones alternativas, que se regulan en el Real Decreto 364/2005. Los incentivos a la contratación consisten en subvenciones por contratos, bonificaciones y exenciones de cuotas, deducciones fiscales y subvenciones a la adaptación de puestos de trabajo. 2. Las destinadas al fomento del autoempleo, que financian proyectos empresariales, proyectos de autoempleo de trabajadores por cuenta propia y conceden subvenciones para la constitución de cooperativas de trabajo asociado o sociedades laborales.

3. El sistema de "empleo con apoyo", que es un conjunto de actividades de orientación y acompañamiento individualizado que prestan preparadores laborales espe-

16. Ministerio de Sanidad, Consumo y Bienestar Social. Extraído el 05/ 06/2020.

https://www.mscbs.gob.es/ssi/discapacidad/informacion/empMasInformacion.htm 
cializados, en el propio puesto de trabajo, a los trabajadores con discapacidad con especiales dificultades de inserción laboral que realizan su actividad en empresas normalizadas, del mercado ordinario de trabajo. Está regulado en el Real Decreto 870/2007.

4. Las fijadas para el empleo público. En este caso, la cuota de reserva de plazas para personas con discapacidad en todas las Administraciones Públicas es del 7 por ciento. Esta cuota se establece en la Ley 7/2007 y se regula para la Administración del Estado en el Real Decreto 2271/2004; de acuerdo con esta norma, en las pruebas selectivas de ingreso a la Administración, las personas con discapacidad disponen de las adaptaciones y los ajustes razonables necesarios de tiempos y medios para su realización, asi como la preferencia en la elección de plazas y la adaptación del puesto de trabajo.

2.1.1. Cuota de reserva de puestos de trabajo del $2 \%$ en las empresas de más de 50 trabajadores $^{17}$

Como ya hemos visto, la LISMI supone un cambio importante en materia de regulación de la situación de las personas con discapacidad en el Estado Español. En cuanto a la integración laboral, entre las diferentes medidas que la misma prevé, la cuota de reserva de puestos de trabajo del $2 \%$ en las empresas de más de 50 trabajadores, supone la asunción por parte del Estado de responsabilizarse de proponer una vía concreta y directa de acceso al empleo en la empresa ordinaria.

La LGD, en su Artículo 42, señala a este respecto:

1. Las empresas públicas y privadas que empleen a un número de 50 o más trabajadores vendrán obligadas a que de entre ellos, al menos, el 2 por 100 sean trabajadores con discapacidad. El cómputo mencionado anteriormente se realizará sobre la plantilla total de la empresa correspondiente, cualquiera que sea el número de centros de trabajo de aquélla y cualquiera que sea la forma de contratación laboral que vincule a los trabajadores de la empresa. Igualmente se entenderá que estarán incluidos en dicho cómputo los trabajadores con discapacidad que se encuentren en cada momento prestando servicios en las empresas públicas o privadas, en virtud de los contratos de puesta a disposición que las mismas hayan celebrado con empresas de trabajo temporal.

17. Ministerio de Trabajo y Asuntos Sociales, Real Decreto 364/2005, de 8 de abril. BOE de 20, de abril de 2005, núm. 94. 
Acceso al empleo de las personas con discapacidad: situación en el empleo en las personas...

(pp. 273-311)

En cuanto a la cuota, muchas empresas utilizan el cálculo de medias normal, sin embargo esto no es correcto, puesto que para el mismo se debe utilizar lo establecido en la disposición adicional primera de los Reales Decretos 27/2000 y 364/2005. Así:

A los efectos del cómputo del dos por ciento de trabajadores con discapacidad en empresas de 50 o más trabajadores, se tendrán en cuenta las siguientes reglas:

a) El periodo de referencia para dicho cálculo serán los 12 meses inmediatamente anteriores, durante los cuales se obtendrá el promedio de trabajadores empleados, incluidos los contratados a tiempo parcial, en la totalidad de centros de trabajo de la empresa.

b) Los trabajadores vinculados por contratos de duración determinada superior a un año se computarán como trabajadores fijos de plantilla.

c) Los contratados por término de hasta un año se computarán según el número de días trabajados en el periodo de referencia. Cada 200 dias trabajados o fracción se computarán como un trabajador más.

Cuando el cociente que resulte de dividir por 200 el número de días trabajados en el citado periodo de referencia sea superior al número de trabajadores que se computan, se tendrá en cuenta, como máximo, el total de dichos trabajadores. A los efectos del cómputo de los 200 días trabajados previsto en los párrafos anteriores, se contabilizarán tanto los días efectivamente trabajados como los de descanso semanal, los días festivos y las vacaciones anuales.

El cumplimiento de la cuota de reserva se puede sustituir por acciones alternativas, que se regulan en el Real Decreto 364/2005. Los incentivos a la contratación consisten en subvenciones por contratos, bonificaciones y exenciones de cuotas, deducciones fiscales y subvenciones a la adaptación de puestos de trabajo.

No es mucha la información en cuanto a resultados concretos sobre la aplicación de la cuota de reserva del $2 \%$, teniendo que retrotraernos al estudio sobre su impacto elaborado por el Ministerio de Trabajo y Asuntos Sociales $(2007)^{18}$. Pese a que el estudio aporta datos anteriores a 2007, es el único con cierto rigor hasta la fecha. Concluye que, si bien el Estado realiza un seguimiento adecuado del cumplimiento de la reglamentación por parte de las empresas de más de 50 trabajadores; la realidad es que la tasa de cumplimiento de la cuota por vía directa se sitúa en el 30,1\% para el $2004,31,7 \%$ para el 2005 y 32,7\% para el 2006, respectivamente. Esto hace suponer

18. Realizado en 2007 en virtud de un Convenio de Colaboración entre el Ministerio de Trabajo y Asuntos Sociales -Secretaría de Estado de Servicios Sociales, Familia y Discapacidad- y la Universidad Carlos III de Madrid. 
que dos tercios de las empresas no cumplían con la cuota en esos años. La limitación del estudio apunta a que se desconoce cuántas de esas empresas han podido acogerse a las medidas alternativas o haber obtenido un certificado de excepcionalidad. Esto hace que dichos datos deban tomarse como aproximativos. A su vez, en el hipotético caso de que el resto de la cuota se cumpliera a través de las medidas alternativas, no deja de ser llamativo que unas medidas promulgadas con carácter excepcional supongan dos tercios de la no aplicación de la cuota, convirtiéndose así la excepcionalidad en la norma.

La imposibilidad de localizar datos de mayor actualidad que muestren el cumplimiento de la cuota nos lleva a tomar información menos desagregada y realizar una interpretación hipotética de la misma. Así, la información más actual la proporciona el Informe Olivenza (Jiménez, 2019) sobre la situación de la discapacidad en España, recogiendo datos de evolución del empleo ordinario desde 2006 hasta 2018: el impacto de la crisis supuso que las contrataciones en el año 2008 sufrieran un descenso considerable en la empresa ordinaria ${ }^{19}$, recuperando poco a poco hasta el año 2015, en el que vuelve a alcanzar valores similares previos a la llegada de la crisis. Así, el número de trabajadores con contratos específicos de discapacidad en empleo ordinario era de 29.033 en el año 2006, descendiendo hasta los 21.135 en el año 2009, recuperándose progresivamente hasta alcanzar en el año 2017 los 27.625, que si bien no llega a los mejores valores previos a la crisis, sí que muestra una recuperación progresiva.

Si habláramos de porcentajes, estaríamos diciendo que en el año 2006 la contratación de personas con discapacidad en la empresa ordinaria llegó a suponer un 32,7\%, alcanzando su nivel más bajo en 2009, con un 23,8\%, recuperándose lentamente hasta alcanzar el $31 \%$ en el año $2017^{20}$. En la misma línea, el "Informe del Mercado de Trabajo de las Personas con Discapacidad"SEPE (2019).

En una situación laboral en la que la tasa de paro entre las personas con discapacidad se situó en 2018 cerca de 10 puntos por encima de la población sin discapacidad, siendo en el mismo ańo la tasa de actividad 44,2 puntos inferior al resto de la población ${ }^{21}$, podemos afirmar que la aplicación real de la cuota de reserva del $2 \%$ en todas las empresas de más de 50 trabajadores, supondría un impulso importante tanto en

19. Consideramos en este caso que un descenso de la contratación en la empresa ordinaria podría extrapolarse a un descenso proporcional en el cumplimiento de cuota.

20. No es posible comparar estos datos con los tomados del estudio Ministerio de Trabajo y Asuntos Sociales (2007), aunque si podemos tomarlos como aproximados y sobre todo referenciados a poder visualizar la tendencia de contrataciones.

21. El empleo de las personas con discapacidad año 2019 - INE. 
el incremento de la tasa de actividad como en la disminución de la tasa de paro de las personas con discapacidad.

La realidad muestra, sin embargo, la reticencia continua por parte de la empresa ordinaria de contratar vía directa a través de la cuota a personas con discapacidad, recurriendo en la mayoría de casos a las medidas alternativas. La causa probablemente tenga que ver con el prejuicio a tener trabajadores fijos en plantilla con discapacidad, optando por la subcontratación con una empresa que siempre pondrá al trabajador más adecuado al puesto que se necesite, respondiendo la empresa subcontratada del trabajador y de su adecuación al puesto de trabajo, dejando de tener la empresa donde el trabajador con discapacidad presta finalmente sus servicios una obligación contractual con él. Por el contrario, durante el mismo periodo los CEE han incrementado su volumen de contrataciones en un $250 \%$, pasando de 26.290 trabajadores en 2006 a 68.613 trabajadores en 2015 (Informe Olivenza, 2019) y 83.604 en 2017 según FEACEM ${ }^{22}$.

Por lo tanto, nos atrevemos a afirmar que la llegada de la crisis supuso un fuerte retroceso de la integración laboral en el mercado ordinario de las personas con discapacidad. Sin embargo, los CEE han incrementado considerablemente el volumen de contrataciones siendo un "refugio" de empleo para las personas con discapacidad. Además, la crisis económica, con la correspondiente precarización del empleo (peores salarios, mayor número de contratos temporales, incremento de los contratos por horas, etc.), puede haber favorecido la reticencia de la empresa ordinaria a la contratación directa del cumplimiento de la cuota a favor de las medidas alternativas, entre las que destaca la subcontratación con CEE.

\subsubsection{La cuota de reserva del $2 \%$ en las personas con enfermedad mental. Situación actual y propuestas}

Conocer la aplicación de la cuota de reserva del $2 \%$ en el caso de las personas con enfermedad mental es prácticamente inviable, no disponemos de datos concretos desagregados en ninguna de las distintas bases.

22. La Federación Empresarial Española de Asociaciones de Centros Especiales de Empleo (FEACEM) es una federación empresarial, sin ánimo de lucro, de ámbito estatal y de carácter intersectorial. FEACEM agrupa a 15 asociaciones empresariales vinculadas al movimiento asociativo de personas con discapacidad, a través de los cuales integra y representa a más de 800 Centros Especiales de Empleo que aglutinan a más de 48.000 trabajadores con discapacidad. Por eso somos la máxima institución representativa y vertebradora de los Centros Especiales de Empleo de Economía Social, de los que asume la interlocución única ante las administraciones públicas, los agentes sociales y la sociedad en general. 
Vista esta limitación, apoyándonos en algunos autores, que tampoco ofrecen datos concretos al hablar de las personas con enfermedad mental en relación al empleo ordinario, vía cuota directa del $2 \%$, podemos proponer algunas suposiciones:

- En primer lugar, la estigmatización que acompaña a las personas con enfermedad mental llega a provocar que, en ocasiones, cuando se trata de empleo normalizado, su situación llegue a ser ocultada tanto al resto de trabajadores como incluso a los propios jefes.

- Las personas con enfermedad mental estarían encuadradas en el subgrupo de personas con discapacidad con especiales dificultades de acceso al trabajo. Para Borja (2019), este colectivo, al igual que el de las personas con discapacidad intelectual, observa grandes dificultades de acceso al empleo ordinario. Mientras que las personas con discapacidad física o sensorial pueden acceder a un trabajo normalizado con una serie de apoyos técnicos o en la forma de trabajar, “... en las personas con discapacidad intelectual y mental el acceso al medio y la comunicación no suele ser el hándicap. Quienes poseen etiologías intelectuales tienen problemas de integración por las dificultades en la comprensión de cada uno de los problemas que surgen diariamente, y las personas con discapacidad mental pueden tener dificultades en el mantenimiento de los hábitos laborales". (Borja, 2015:394)

- Las personas con enfermedad mental, además de personas con una discapacidad, son personas con una enfermedad. Esta puede cursar con episodios en forma de brotes que junto a la necesidad continua de control médico psiquiátrico, contribuyen a que sean percibidas por parte de la empresa ordinaria como susceptibles de constantes ausencias en el puesto de trabajo debidas a la supervisión médica y a las previsibles bajas laborales, suponiendo por lo tanto una complicación añadida.

En términos absolutos en datos del Informe del INE sobre el Empleo de las Personas con Discapacidad (2018) en comparación con el resto de tipos de discapacidad las personas con enfermedad mental tienen la tasa de empleo más baja $(22,3 \%)$. Hemos de tener en cuenta que este dato corresponde al total de ocupadas a través de las distintas modalidades de inserción laboral (solo personas que cotizan a la TGSS); si consideramos además que están encuadradas dentro del colectivo de personas con discapacidad con especiales dificultades de acceso al trabajo, podríamos suponer que, cuando se trate exclusivamente de empleo normalizado, este porcentaje es susceptible de disminuir considerablemente.

Tras el análisis de la situación de las personas con enfermedad mental y como propuestas de mejora en su empleabilidad, podríamos señalar las siguientes: 
- Refuerzo de las medidas existentes de transición del empleo protegido al ordinario con un control más exhaustivo de las cuotas de reserva incluyendo un porcentaje concreto de contratación de personas con enfermedad mental en aquellas empresas en que fuese posible por número de trabajadores.

- Posibilidad de incentivos específicos a la empresa para la contratación de personas con enfermedad mental para favorecer su inclusión laboral.

- Favorecer el empleo con apoyo con preparadores laborales con un conocimiento específico del colectivo y peculiaridades de las personas con enfermedad mental.

- Las personas con enfermedad mental tienen no solo las tasas de empleo más bajas con respecto al resto de discapacidades, sino también las tasas de actividad más bajas (INE, 2016) ${ }^{23}$. La dificultad de trabajar sobre las tasas de empleo es obvia (influencia de múltiples factores, contextos económicos y políticos); sin embargo, puede ser más viable incrementar las tasas de actividad, favoreciendo una mayor incorporación de las personas con enfermedad mental al mercado de trabajo a través de la formación y capacitación para el empleo ${ }^{24}$.

\subsubsection{El acceso al empleo público en las personas con discapacidad}

Como garante de los derechos de las personas con discapacidad, la administración pública debe ser ejemplo en el cumplimiento de las leyes que promulga. Por ello, dentro de su responsabilidad social y en relación al fomento del empleo público para personas con discapacidad, busca ceñirse a las normas internacionales incrementando la cuota del $2 \%$ por encima de la norma española ${ }^{25}$.

La Convención Internacional de los Derechos de las Personas con Discapacidad marca una cuota de reserva superior a las que las leyes estatales contemplan para el

23. INE, "El empleo de las personas con discapacidad, 2015", http://www.ine.es/prensa/np1012.pdf

24. En este sentido podemos poner como ejemplo los resultados del análisis del programa de Itinerarios de Empleo de la Federación de Salud Mental de Castilla y León en el que se muestran datos sobre la incidencia indirecta de dicho programa en las tasas de empleo, así: "Haciendo el ejercicio de extrapolar los datos del programa de Itinerarios de Empleo para compararlos con los de INE a nivel general se aprecia que, con este modelo de trabajo, se ha conseguido una tasa de empleo del 42 ' $65 \%$ calculada sobre las personas con las que dicha Federación trabaja. Es decir tres de cada siete personas en Itinerarios de Empleo encuentran trabajo. Sin embargo el resto, esas cuatro de cada siete restantes, al menos están activas y participan en programas de autonomía personal, de formación para el empleo y de ocio, entre otros." Confederación de Salud Mental de España (2018:95).

25. La Convención Internacional de los Derechos de las Personas con Discapacidad marca una cuota de reserva superior a las que las leyes españolas contemplan para las empresas privadas de 50 o más trabajadores. Como ya hemos indicado al inicio, la evolución de la norma en relación a dicha cuota de reserva ha estado referenciada al sucesivo cumplimiento de las normativas internacionales. 
resto de empresas de 50 o más trabajadores. Como ya hemos indicado al inicio, la evolución de la norma en relación a dicha cuota de reserva ha estado referenciada al sucesivo cumplimiento de las normativas internacionales.

El marco normativo que regula el acceso a la función pública de las personas con discapacidad se fundamenta en la Ley General de derechos de personas con discapacidad del año 2013 (RD Legislativo 1/2013, de 29 de noviembre, por el que se aprueba el Texto Refundido de la Ley General de derechos de las personas con discapacidad y de su inclusión social), así, en su artículo 42 establece lo siguiente en relación a la cuota de reserva de puestos de trabajo para personas con discapacidad: "Las empresas públicas y privadas que empleen a un número de 50 o más trabajadores vendrán obligadas a que de entre ellos, al menos, el 2 por 100 sean trabajadores con discapacidad".

La evolución normativa sobre dicha materia nos lleva en un primer momento a la Ley 30/1984, de 2 de agosto, de Medidas para la Reforma de la Función Pública, establece una cuota de reserva para las Ofertas de Empleo Público de un 3\%, comenzando de esta manera a incrementar dicha cuota, en relación a la cuota del $2 \%$ que venía estableciendo la LISMI (1982).

Posteriormente, el RD 2271/2004, de 3 de diciembre, de Acceso al Empleo Público y Provisión de puestos de trabajo de Personas con Discapacidad, viene a introducir una nueva modificación, estableciendo una cuota de reserva en las ofertas de empleo público no inferior al $5 \%$.

La Ley 26/2011, de 1 de agosto, de Adaptación Normativa a la Convención Internacional sobre los Derechos de las Personas con Discapacidad, modifica el artículo 59 del Estatuto Básico del Empleado Público, elevando el porcentaje de la cuota al $7 \%$, con la novedad, en este caso, de incluir que al menos un $2 \%$ sea ocupado por personas con discapacidad intelectual.

Dicha norma, especifica también que su alcance incluye la administración estatal, la autonómica y la local. Asimismo, se establece la posibilidad de incrementar en siguientes convocatorias el porcentaje de plazas ofertadas, siempre que no se cubran en la anterior, no siendo superior en su caso al $10 \%$ de plazas ofertadas.

En la Encuesta sobre el Empleo de las Personas con Discapacidad (SEPE, 2019), elaborada por el INE, los datos en el ítem "Administración Pública y defensa; Seguridad Social obligatoria" nos muestra un $9 \%$ de diferencia en cuanto a la contratación de personas con discapacidad en relación al resto de ramas de actividad.

El Real Decreto Legislativo 5/2015, de 30 de octubre, por el que se aprueba el texto refundido de la Ley del Estatuto Básico del Empleado Público, en su artículo 59 regula una reserva del $7 \%$, siendo el $2 \%$ para personas con discapacidad intelectual. 
Artículo 59. Personas con discapacidad.

1. En las ofertas de empleo público se reservará un cupo no inferior al siete por ciento de las vacantes para ser cubiertas entre personas con discapacidad, considerando como tales las definidas en el apartado 2 del articulo 4 del texto refundido de la Ley General de derechos de las personas con discapacidad y de su inclusión social, aprobado por el Real Decreto Legislativo 1/2013, de 29 de noviembre, siempre que superen los procesos selectivos y acrediten su discapacidad y la compatibilidad con el desempeño de las tareas, de modo que progresivamente se alcance el dos por ciento de los efectivos totales en cada Administración Pública.

La reserva del minimo del siete por ciento se realizará de manera que, al menos, el dos por ciento de las plazas ofertadas lo sea para ser cubiertas por personas que acrediten discapacidad intelectual y el resto de las plazas ofertadas lo sea para personas que acrediten cualquier otro tipo de discapacidad.

2. Cada Administración Pública adoptará las medidas precisas para establecer las adaptaciones y ajustes razonables de tiempos y medios en el proceso selectivo y, una vez superado dicho proceso, las adaptaciones en el puesto de trabajo a las necesidades de las personas con discapacidad.

\subsubsection{Empleo público y personas con enfermedad mental. Situación y propuestas}

Si bien la encuesta sobre el Empleo de las Personas con Discapacidad (INE, 2019) y los informes de ODISMET ${ }^{26}$ sí que discriminan entre personas con discapacidad intelectual y personas con enfermedad mental en cuanto a las tasas de actividad, empleo y paro; el informe Olivenza 2019 y la base de datos del SEPE (Servicio Público Estala de Empleo) las incluyen dentro del subgrupo de discapacidades psíquicas. Dichas discrepancias pueden contribuir a la confusión, en ocasiones, entre discapacidad intelectual y enfermedad mental y, en su caso, a la falta de medidas y apoyos específicos para las personas con enfermedad mental.

A la vez, tal y como se desprende del Real Decreto Legislativo 5/2015, de 30 de octubre, podemos considerar que las personas con enfermedad mental se quedan en una clara situación de desventaja con respecto a -por ejemplo- las personas con discapacidad intelectual, a las que si se les reserva una cuota específica del $2 \%$.

26. Es lógico que sea así, puesto que ODISMET utiliza datos del INE para realizar sus informes, además es important señalar que si bien el Informe 4, utiliza el término "mental" al referirse al grupo de personas con enfermedad mental, el Informe 5, ya incluye la denominación aconsejada por la OMS en las que se refiere al mismo grupo de discapacidades como "psicosocial". 
El estudio sobre el impacto de la cuota de reserva elaborado por el Ministerio de Trabajo y Asuntos Sociales (2007) anteriormente mencionado, muestra algunos aspectos interesantes a tener en cuenta cuando hablamos de las personas con discapacidad, concretamente de las personas con enfermedad mental, en la función pública:

- Si bien la oferta de plazas supera ampliamente la cuota de reserva, en realidad no es así en todos los cuerpos y categorías; en parte porque hay puestos en los que la limitación supone un obstáculo insalvable, pero también porque en ocasiones no se plantea la posibilidad de adaptar el puesto de trabajo a la persona.

- La crisis de 2008 ha provocado en los últimos años una reducción en la oferta pública de empleo. Esto también ha afectado a las personas con discapacidad al verse reducidas en la misma proporción las plazas ofertadas en relación a la cuota.

Como propuesta principal en relación a la cuota, se podría reservar un porcentaje específico para personas con enfermedad mental. En este sentido, si bien una reserva específica del $2 \%$ podría ser adecuada tal y como plantea entre algunas de sus propuestas la Confederación de Salud Mental de España a través de su informe anual (2017), podemos ir avanzando hacia la misma y tomar como ejemplo la Comunidad de Andalucía, en la que se ha aprobado la Ley 4/2017, de 25 de septiembre, de los Derechos y la Atención a las Personas con Discapacidad en Andalucía, que obliga a que del porcentaje del $2 \%$ anteriormente destinado a personas con discapacidad intelectual, un $1 \%$ sea para las personas con enfermedad mental.

\subsubsection{El trabajo por cuenta propia de las personas con discapacidad}

La crisis de 2008 supuso para el empleo una reestructuración de la relación entre capital y trabajo a todos los niveles. La misma ha hecho perder peso específico a los sindicatos en la negoción colectiva, expresándose esa pérdida de capacidad, por ejemplo, en el abaratamiento de los despidos, la proliferación de minijobs, así como en un deterioro de las relaciones laborales.

Otra de las situaciones generadas al calor de la crisis, ha sido el incremento del autoempleo. Bajo la forma del emprendimiento, muchas empresas han encontrado la posibilidad de mantener relaciones contractuales con sus trabajadores sin el compromiso de su contratación, apareciendo la figura conocida en términos coloquiales como "falso autónomo". Calvo (2005), desarrolla el concepto de trabajador autónomo dependiente como aquel que mantiene una dependencia económica pero no jurídica con respecto a la empresa que lo contrata. Generándose una situación de 
precariedad en la situación del trabajador fruto de la indefensión hacia las vicisitudes coyunturales del trabajo que realice.

El Comité Económico y Social Europeo establece una serie de recomendaciones, respecto al empleo autónomo, en las que viene a concluir que es necesario delimitar lo que es claramente empleo autónomo por cuenta propia elegido voluntariamente frente al "falso autónomo" por lo que supone de fraude a la seguridad social, competencia desleal frente a pymes y autónomos de buena fe. Siecker (2013) afirma que los trabajadores autónomos son una "capa flexible" de la mano de obra caracterizada por relaciones de trabajo poco estables y con facilidad para ser rotas si la situación económica lo requiere.

La legislación básica que regula el empleo por cuenta propia son la Ley 20/2007, de 11 de julio, del Estatuto del trabajo autónomo y la ley 6/2017, de 24 de octubre, de Reformas Urgentes del Trabajo Autónomo.

En relación a las personas con discapacidad la normativa que regula la promoción y fomento del empleo autónomo tiene su última actualización en la LGD (2012); si bien, las competencias sobre las medidas de fomento del empleo están transferidas a las comunidades autónomas, que son las que finalmente desarrollan las ayudas concretas y específicas tal y como señala el artículo 47: "Los poderes públicos, en el ámbito de sus respectivas competencias, adoptarán politicas de fomento del trabajo autónomo de personas con discapacidad dirigidas al establecimiento y desarrollo de iniciativas económicas y profesionales por cuenta propia, o a través de entidades de la economía social, de acuerdo con la normativa reguladora de la materia. Ley general de discapacidad".

A su vez, la disposición Final Sexta de la Ley 43/2006 de 29 de Diciembre para la mejora y el crecimiento del empleo que viene a modificar la Ley 45/2002 de 12 de diciembre establece en relación a las personas con discapacidad con alta inicial en el Régimen Especial de la Seguridad Social, ya sea como trabajador autónomo o por cuenta propia, una bonificación del 50\% de la cuota que resulte de aplicar sobre la base mínima el tipo vigente en cada momento en dicho Régimen, durante los cinco ańos siguientes a la fecha de alta.

En la actualidad, la Ley 11/2013, de 26 de julio, de medidas de apoyo al emprendedor y de estímulo del crecimiento y de la creación de empleo, contempla una serie de bonificaciones y reducciones durante 5 años aplicables a la cuota de contingencias comunes:

- Personas con un grado de discapacidad igual o superior al 33\% que causen alta inicial en el Régimen Especial de Autónomos.

* Reducción del 80\% durante 6 meses si no tiene asalariados.

* Bonificación del 50\% durante 54 meses. 
- Personas con un grado de discapacidad igual o superior al 33\%, menores de 35 ańos que causen alta inicial o no hubieran estado de alta en los 5 ańos inmediatamente anteriores, sin trabajadores por cuenta ajena.

* Reducción del 80\% durante 12 meses.

* Bonificación del 50\% durante los 4 años siguientes.

\subsubsection{El trabajo por cuenta propia en personas con enfermedad mental. Situación y} propuestas

Las personas con enfermedad mental, al igual que el resto de personas con discapacidad, van a tener a su alcance otras modalidades de empleo más sencillas que el trabajo por cuenta propia para acceder al mercado laboral, que sin embargo es una opción posible. Del informe del SEPE (2019) extraemos los siguientes datos: de un total de 2.033.650 trabajadores por cuenta propia, 33.800 lo serían con algún tipo de discapacidad, esto supone un 1,7\% aproximadamente. También, en términos globales dentro de las personas con discapacidad, si comparamos el porcentaje de trabajadores con cuenta propia frente al resto de modalidades de empleo, esto supone un $11,4 \%$ del total de personas con discapacidad en situación de empleo. Además, a la hora de optar por el empleo por cuenta propia, los porcentajes varían considerablemente, dependiendo de la tipología de la discapacidad de la que estemos hablando, como muestra la tabla a continuación:

Tabla 3.

Personas con discapacidad trabajando por cuenta propia en España en 2018

\begin{tabular}{|l|c|c|}
\hline Tipo de discapacidad & No absoluto & Porcentaje \\
\hline Física y otras & 17.200 & $52,4 \%$ \\
\hline Intelectual & 700 & $2,1 \%$ \\
\hline Mental & 2.600 & $7,9 \%$ \\
\hline Visual & 1.200 & $3,7 \%$ \\
\hline Auditiva & 4.100 & $12,5 \%$ \\
\hline No consta & 7.000 & $21,3 \%$ \\
\hline Total & 32.800 & $100,0 \%$ \\
\hline
\end{tabular}

Fuente: Informe Olivenza 2019. Datos del INE sobre el empleo de las personas con discapacidad mercado de trabajo en las personas con discapacidad 2017 (Informe Olivenza 2019:366). 
Como podemos observar, las personas con una discapacidad física van a ser las que en su mayoría opten por el autoempleo, alcanzando un porcentaje del $52,4 \%$. El $47,6 \%$ restante se distribuye entre el resto de tipos de discapacidad.

En el caso de las personas con enfermedad mental, el porcentaje alcanzó un 7,9\% para el año 2017. En valores absolutos, según estadísticas del INE, en el año 2017, 2.600 personas con enfermedad mental optaron por el autoempleo como opción laboral en todo el Estado.

Estos resultados muestran que la opción del autoempleo en el caso de dicho colectivo de discapacidades, no es especialmente significativa. Una de las posibles causas puede tener que ver con que la persona que opta por el autoempleo suele ser alguien con un perfil en el que la formación pre-laboral o en su caso adquisición de competencias previas específicas juegan un papel importante. En el caso de las personas con enfermedad mental, es necesario considerar que la aparición del trastorno o primer brote suele ser a finales de la adolescencia o inicios de la juventud, lo que hace que, en la mayoría de los casos, se haya interrumpido el proceso formativo o que apenas haya dado tiempo para la adquisición de hábitos y conocimientos laborales.

Como medida que podría favorecer la opción del empleo por cuenta propia de las personas con discapacidad en general y con enfermedad mental en particular, podríamos seguir las indicaciones del Plan de Acción de la Estrategia Española de Discapacidad 2014-2020 reforzando las medidas de apoyo a las personas con discapacidad que trabajen por cuenta propia. García (2016) propone que el empleo por cuenta propia sea subvencionado de forma indefinida teniendo en cuenta los diferentes grados y tipos de discapacidad.

\subsubsection{Los programas de empleo con apoyo}

El empleo con apoyo es un modelo que se basa en la inclusión de la persona con discapacidad en el mercado laboral ordinario a través de los apoyos necesarios tanto dentro como fuera del lugar de trabajo. Sus inicios se remontan a los años 80 en EE.UU., para pasar a finales de los 90 a Europa (Becerra, Fernández y Lucero, 2012). Se ha definido como "empleo remunerado en lugares de la comunidad, con apoyos individualizados y continuados que asegura el éxito a largo plazo, y en el que existan claras oportunidades para la interacción con personas sin discapacidad" (Mank, 1998: 8). Son tres los aspectos que debe incluir el empleo con apoyo: trabajo remunerado, apoyos continuados y en entornos integrados. De Urríes, Verdugo y Pulido (2012) señalan que la función del empleo con apoyo a personas con discapacidad tiene como objetivo garantizar y mantener un empleo remunerado en el mercado 
libre de trabajo. Para Bond, Evans y Salyers (2000), uno de los aspectos clave que deberían incluir los programas de empleo ordinario con apoyo, sería el de un apoyo ilimitado en el tiempo para personas con especiales dificultades de acceso al empleo (como es el caso de las PTMG).

Si atendemos a las inversiones públicas, podemos observar cómo la mayoría del gasto se focaliza a través de los CEE por lo que es presumible afirmar que el empleo normalizado con apoyo (a través de vía directa en empresa ordinaria) es significativamente menor. Los datos del Informe de ODISMET sobre el empleo de las personas con discapacidad (2018), muestran que para el año 2017, más del $90 \%$ de la inversión dirigida al empleo con apoyo estuvo destinada al mantenimiento de puestos de trabajo en CEE. Así, el propio informe expresa que para el ańo 2017, el número de beneficiarios de ayudas concedidas a la integración laboral de personas con discapacidad es de 95.323.241, siendo en su mayoría para el mantenimiento del puesto de trabajo en CEEs (83.604).

Podemos definir el empleo con apoyo como el conjunto de actividades de orientación y acompańamiento individualizado que prestan, en el propio puesto de trabajo, preparadores laborales especializados a los trabajadores con discapacidad con especiales dificultades de inserción laboral que realizan su actividad en empresas normalizadas, del mercado ordinario de trabajo, en condiciones similares al resto de los trabajadores que desempeñan puestos similares.

La reglamentación por la que se regula el empleo con apoyo en el mercado ordinario aparece en el artículo 2 del RD 870/2007, de 2 de julio, así:

1. Se entiende por empleo con apoyo el conjunto de acciones de orientación y acompañamiento individualizado en el puesto de trabajo, prestadas por preparadores laborales especializados, que tienen por objeto facilitar la adaptación social y laboral de trabajadores con discapacidad con especiales dificultades de inserción laboral en empresas del mercado ordinario de trabajo en condiciones similares al resto de los trabajadores que desempeñan puestos equivalentes.

2. Las acciones de empleo con apoyo se desarrollarán en el marco de proyectos de empleo con apoyo, en los que deberán contemplarse, al menos, las siguientes acciones:

a) Orientación, asesoramiento y acompañamiento a la persona con discapacidad, elaborando para cada trabajador un programa de adaptación al puesto de trabajo. b) Labores de acercamiento y mutua ayuda entre el trabajador beneficiario del programa de empleo con apoyo, el empleador y el personal de la empresa que comparta tareas con el trabajador con discapacidad. 
c) Apoyo al trabajador en el desarrollo de habilidades sociales y comunitarias, de modo que pueda relacionarse con el entorno laboral en las mejores condiciones. d) Adiestramiento especifico del trabajador con discapacidad en las tareas inherentes al puesto de trabajo.

e) Seguimiento del trabajador y evaluación del proceso de inserción en el puesto de trabajo. Estas acciones tendrán por objeto la detección de necesidades y la prevención de posibles obstáculos, tanto para el trabajador como para la empresa que le contrata, que pongan en peligro el objetivo de inserción y permanencia en el empleo

f) Asesoramiento e información a la empresa sobre las necesidades y procesos de adaptación del puesto de trabajo.

Existen además una serie de incentivos económicos a las empresas, que varían de acuerdo al tipo de contrato, tiempo de duración y tipo y grado de discapacidad. Otro aspecto importante es que el marco regulador, varía también dependiendo de la Comunidad Autónoma en la que nos situemos.

\subsubsection{Empleo con apoyo y personas con enfermedad mental. Situación actual y propuestas}

Los datos disponibles, una vez más, solo muestran aquellos contratos en los que previsiblemente existe algún tipo de ayuda, pero no si se trata de medidas de empleo con apoyo (más allá de las bonificaciones), así como tampoco reflejan la tipología de discapacidad de los contratos.

Podemos presuponer que las características específicas de las personas con enfermedad mental, insertas en el colectivo de personas con discapacidad con especiales dificultades de acceso al trabajo junto con las personas con una discapacidad intelectual, se enfrentan a obstáculos importantes para su incorporación en la empresa ordinaria, como podremos ver en el análisis y conclusiones.

Si bien son pocos los estudios sobre la incidencia del empleo con apoyo en personas con enfermedad mental, sí que podemos señalar algunos. Así, como experiencias fuera de nuestro país, algunos estudios realizados en EE.UU. y Canadá ya hace un par de décadas, señalan porcentajes elevados de éxito de esta modalidad de empleo. Sin embargo, también apuntan a que este éxito se relaciona directamente con bajas tasas de paro (Álvarez, 2003). 
Verdugo (1998) ya señala que los programas de rehabilitación laboral de apoyo y la colocación individual selectiva son efectivos para ayudar a la persona con enfermedad mental a conseguir un empleo adecuado. Por su parte, Pulido y Ramírez (2004) clasifican en tres grandes grupos las dificultades principales con las que se encuentran las personas con enfermedad mental para su incorporación a la empresa normalizada: "El primer grupo se incluyen aquellas dificultades derivadas del prejuicio social; el segundo grupo está compuesto por las dificultades derivadas de la propia enfermedad, como las dificultades a la hora de elegir, de conseguir y de conservar un empleo; y un tercer lugar formado por las dificultades derivadas de la situación del mercado laboral" (Pulido \& Ramírez, 2004:270).

Esteban y Jordán de Urríes (2006), establecen una comparación diferencial entre la aplicación del modelo de Empleo con Apoyo al colectivo de personas con discapacidad intelectual y las personas con trastorno mental. Estos mismos autores concluyen la importancia y necesidad de un análisis diferenciado en cada caso, para la consecución de una correcta adaptación de la persona con discapacidad al puesto de trabajo.

En cuanto a datos concretos del impacto del empleo con apoyo en España, podemos retrotraernos a un estudio elaborado por el Observatorio Estatal de la Discapacidad (2018) en colaboración con la Asociación Española de Empleo con Apoyo (AESE), en $2016^{27}$. Como dato principal a tener en cuenta en relación a las personas con enfermedad mental, durante, 2016 el 67,3\% de las personas con enfermedad mental del estudio fueron contratadas a jornada completa, mientras que en el caso de las personas con discapacidad intelectual, el porcentaje de contratos indefinidos fue de un $36,5 \%$. Si bien los resultados del estudio pueden ser tenidos en cuenta de una manera relativa, sí que muestra un dato que conviene resaltar, y es el del porcentaje de contratos indefinidos con respecto a otra tipología de discapacidades, lo que puede dar a entender que el empleo con apoyo, con las consideraciones tenidas en cuenta a continuación en relación a los apoyos continuados en el tiempo, puede ser una opción valiosa para la inclusión laboral de personas con enfermedad mental en empleo ordinario a través del empleo con apoyo.

Como propuestas concretas, podemos incluir algunos aspectos del informe anterior: así aparece la necesidad de incluir a la familia en los procesos de inclusión y el apoyo y supervisión del preparador laboral durante la fase de adaptación.

El empleo con apoyo, aunque no de forma exclusiva, es un mecanismo de transición del empleo protegido al empleo ordinario. Algunos autores, con la intención de 
favorecer esa transición, han propuesto fijar bonificaciones también en caso de contratación temporal estructural por obra o servicio y eventual (actualmente limitado a un mínimo de 6 meses tal y como se ha indicado), atendiendo al uso frecuente de estas tipologías de contrato en los procesos de inserción mediante empleo (Fernández, 2016).

\subsection{El empleo protegido}

El empleo protegido es una modalidad laboral para aquellas personas que por su discapacidad no pueden acceder al mercado ordinario de trabajo. Es uno de los tipos de empleo que contempla el artículo 37.2.b) de la LGPD, considerando tales los que se lleven a cabo en los centros especiales de empleo y a través de los enclaves laborales.

\subsubsection{Los Centros Especiales de Empleo}

Los Centros Especiales de Empleo (CEE) pasan por ser, sin lugar a dudas, la principal herramienta de inclusión en el ámbito del trabajo de las personas con discapacidad. Surgen al amparo de la Ley de Integración Social de las Personas con discapacidad (LISMI) de 1982 y son una modalidad de empresas que tienen el objetivo de integrar laboralmente a personas con discapacidad. Esto obliga a que el $70 \%$ de su plantilla está conformada por personas con al menos un 33\% de discapacidad.

Las estadísticas que veremos a continuación con más detalle muestran que las personas con discapacidad contratadas en CEE en toda España suponen cerca del $25 \%$ del total de personas con discapacidad en situación de alta laboral.

Es importante destacar el concepto de empresa, que implica la realización de una actividad remunerada sujeta al mercado y bajo las garantías y obligaciones que ello conlleva, diferenciándose de un modo claro de los talleres y centros ocupacionales ${ }^{28}$.

28. Los centros ocupacionales surgieron en los ańos sesenta y setenta por iniciativa de asociaciones de padres y familiares de personas con discapacidad intelectual. En sus inicios, estos centros tenían una perspectiva docente puesto que el apoyo principal era brindado por maestros de educación especial, como salida a la finalización de la educación especial obligatoria. Sin embargo, con el paso del tiempo se ha abandonado la orientación educativa por una orientación de carácter más profesional. Los centros ocupacionales se han configurado como una de las principales opciones formativas, ocupacionales y laborales para las personas con discapacidad que no pueden acceder al empleo y, sin lugar a dudas, han permitido dar un salto cualitativo en la concepción de las personas con discapacidad intelectual en su fututo rol de trabajador (COCEMFE). Extraído el 01/06/2020 de URL: http://www.cocemfecyl.es/index.php/prestaciones-sociales/58-empleo-ociones-de-empleabilidad/208-centros-ocupacionales 
El desarrollo de los CEE en España parte de la Ley 13/1982, de 7 de abril, de Integración Social del Minusválido (LISMI). En su artículo 37, aparece por primera vez la nomenclatura de Centro Especial de Empleo para referirse a una modalidad de empleo protegido que más adelante se convertirá en la principal herramienta de inclusión laboral de las personas con discapacidad. El artículo 41 señala que "los minusválidos que por razón de la naturaleza o de las consecuencias de sus minusvalías no puedan, provisional o definitivamente, ejercer una actividad laboral en las condiciones habituales, deberán ser empleados en Centros Especiales de Empleo" (Ley 13/1982, de 7 de abril, art. 41).

La reglamentación y regulación posterior de los CEE culmina con la derogación de la LISMI, en 2013 en base al RD Legislativo 1/2013, de 29 de noviembre, por el que se aprueba el Texto Refundido de la Ley General de derechos de las personas con discapacidad y de su inclusión social (LGD).

En su artículo 43, nos encontramos una definición actualizada que muestra la evolución del concepto de CEE adaptada a la realidad actual y en la que se detallan aspectos como su fin empresarial y el porcentaje de personas con discapacidad en su plantilla. Como podemos ver, también se presta especial atención a las unidades de apoyo y ajuste personal como elemento que va a ser clave, sobre todo para personas con discapacidad con especiales dificultades para su inclusión laboral. El artículo 43.1 dice así: "Los centros especiales de empleo son aquellos cuyo objetivo principal es el de realizar una actividad productiva de bienes o de servicios, participando regularmente en las operaciones del mercado, y tienen como finalidad el asegurar un empleo remunerado para las personas con discapacidad; a la vez que son un medio de inclusión del mayor número de estas personas en el régimen de empleo ordinario. Igualmente, los centros especiales de empleo deberán prestar, a través de las unidades de apoyo, los servicios de ajuste personal y social que requieran las personas trabajadoras con discapacidad, según sus circunstancias y conforme a lo que se determine reglamentariamente." (RD Legislativo 1/2013, de 29 de noviembre, art. 43).

En cuanto a cifras, como señalábamos con anterioridad, los CEE vienen a suponer la medida de mayor valor cuantitativo en cuanto a la inclusión laboral de personas con discapacidad en toda España. Las cifras no dejan lugar a duda: el informe ODISMET (2019), que utiliza datos del SEPE 2018 señala que en 2019 se realizaron un total de $117.818^{29}$ contrataciones específicas a personas con discapacidad, que suponen una tasa del $18 \%$ en relación con el total de la población activa con disca-

29. Como se señala en las conclusiones del propio informe, hay que señalar que los contratos específicos a personas con discapacidad, no representan el total de la contratación del colectivo (suponen en torno al 40\%), sin embargo, son un indicador claro de la importancia que representa para las personas con discapacidad, la protección contractual en el empleo. 
pacidad. Los Centros especiales de empleo (CEEs) sumaron 83.408 contrataciones, lo que equivale al $12,7 \%$ de la población activa y el $71 \%$ de todos los contratos específicos realizados durante el año a las personas con discapacidad.

\section{Gráfico 1.}

\section{Comparativa de personas con discapacidad en CEE y empleo ordinario en} España entre 2006 y 2019

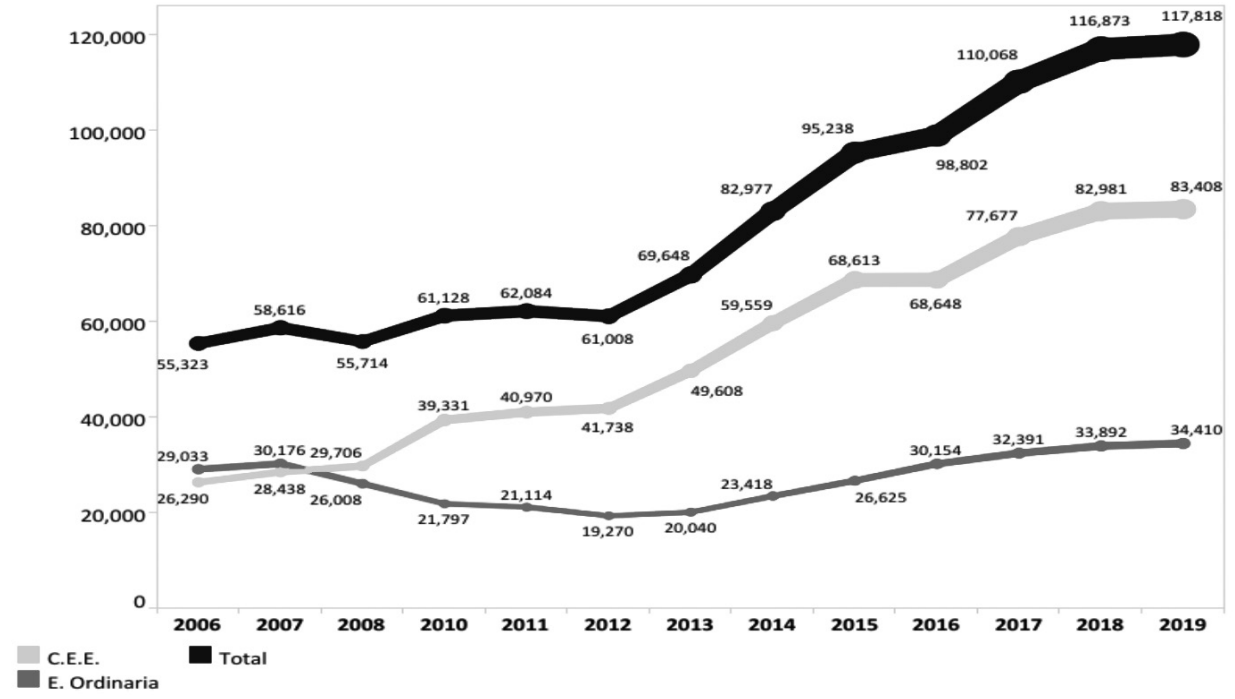

Fuente: Informe 1.09. Volumen de contratos específicos realizados a personas con discapacidad (ODISMET 2019).

Además de la consolidación de los CEE por el importante apoyo estatal, un aspecto que ha tenido una especial incidencia en el incremento de las plantillas de los CEE a partir de 2008 es que se han convertido en focos de empleo de mayor estabilidad para las personas con discapacidad. Como apuntan Barea y Monzón (2008), los CEE se convierten en ese momento en la más importante palanca para la inserción laboral de las personas con discapacidad en España.

2.2.2. Las personas con enfermedad mental en los Centros Especiales de Empleo (CEE). Situación actual y propuestas

Con respecto a la situación de personas con enfermedad mental en CEE, si bien podría ser relativamente sencillo el poder acceder a datos específicos sobre las tipolo- 
gías de la discapacidad en CEE, en realidad nos encontramos con diferentes bases de datos: el informe 5 de Odismet y el observatorio de las discapacidades no muestran datos desagregados por tipologías de discapacidades en relación a los CEE. El Informe sobre el Empleo de las Personas con Discapacidad (2018), con datos del INE, excluye explícitamente en sus tablas información sobre los CEE. El informe Olivenza 2019, tampoco ofrece datos segregados sobre las tipologías de discapacidades en CEE.

Esto se debe, en parte, a la transferencia del registro, control y seguimiento de los CEE, que está transferido las Comunidades autónomas. Una consulta a través de la plataforma de Labora - Generalitat Valenciana ${ }^{30}$, realizada en octubre de 2019, solicitando datos sobre tipologías de discapacidad en CEE, nos remite a información de Odismet y nos indica que no disponen de los datos desagregados.

En este sentido y con respecto a propuestas específicas orientadas a la mejora de la situación de las personas con enfermedad mental en CEE, podríamos señalar que sería necesario poder segregar los datos de personas con discapacidad intelectual de los de las personas con enfermedad mental ${ }^{31}$. Esto nos llevaría a poder tener una radiografía veraz del volumen que representan y de ese modo implementar los apoyos necesarios. Si bien, ninguno de los informes que hemos trabajado incluyen datos al respecto, para las administraciones autonómicas podría ser relativamente sencillo conseguirlos, simplemente tabulando los datos de los TC2 de las memorias anuales que los CEE deben entregar en su justificación, puesto que en los mismos aparecen detallados el tipo de discapacidad de cada trabajador.

\subsubsection{Los Enclaves Laborales}

Los enclaves laborales son una medida específica de apoyo a la inclusión y aparecen con la intención de avanzar hacia la integración laboral de las personas con discapacidad en el entorno normalizado de la empresa ordinaria. Como señalan Senra y Valdés (2004), el enclave laboral es un paso más hacia la igualdad y la inclusión. Se constituye entre una empresa ordinaria (empresa colaboradora) y un CEE con el objeto de realizar obras o servicios que tengan una relación directa con la actividad empresarial principal.

30. Labora - Generalitat Valenciana es la agencia de empleo autónomica de la Comunidad Valenciana.

31. FEACEM. Información ofrecida por Pepa Torres, gerente de FEACEM (2017), en el seminario sobre CEE del módulo Entidades de acción social y voluntariado, del Máster de Economía Social y Cooperativas de la Universidad de Valencia, curso 2016/2017. 
Son una forma de acercar a los trabajadores con discapacidad al empleo ordinario, facilitando en contacto con el entorno normalizado. Se materializan en una subcontratación en la que los trabajadores con discapacidad del CEE se desplazan durante un tiempo a la empresa colaboradora para realizar la actividad laboral designada.

Los enclaves laborales surgen en el espíritu de la LISMI para dar salida a su artículo 38 (posteriormente reconvertido en el artículo 42 de la LGD).

Para el cumplimiento de dicho artículo, con posterioridad se establecen una serie de medidas alternativas a la contratación directa de la cuota del 2\%, así en 2004, se articulan los enclaves laborales promulgándose el real decreto 290/2004.

En su artículo 1, apartado 2 aparece: “... Se entiende por enclave laboral el contrato entre una empresa del mercado ordinario de trabajo, llamada empresa colaboradora, y un centro especial de empleo para la realización de obras o servicios que guarden relación directa con la actividad normal de aquélla y para cuya realización un grupo de trabajadores con discapacidad del centro especial de empleo se desplaza temporalmente al centro de trabajo de la empresa colaboradora." (RD 290/2004, de 20 de febrero, art. 1).

\subsubsection{Las personas con enfermedad mental y los enclaves laborales. Situación actual y propuestas}

Hablar de personas con discapacidad es hacerlo de un colectivo heterogéneo en cuanto a problemáticas y dificultades. Dentro del mismo, las personas con trastorno mental se encuentran encuadradas entre los trabajadores/as con discapacidad con especiales dificultades para la inserción.

Desde esta perspectiva y teniendo en cuenta además que las personas con trastorno mental, como hemos visto con anterioridad, mejoran sus posibilidades de integración laboral cuando existe una supervisión a través del personal de apoyo y una adaptación inclusiva del puesto de trabajo a la misma, podríamos considerar a los enclaves laborales espacios óptimos de acercamiento al empleo normalizado.

Sin embargo, los "engorrosos" y complicados procesos administrativos a la hora de configurar un enclave entre un CEE y una empresa ${ }^{32}$, hacen que esta modalidad tenga una menor incidencia de la deseada. En este caso, la limitación no estaría en la situación de enfermedad mental, sino en otros tipos de aspectos relacionados con el modo en el que se constituye. Así, el tiempo de duración debe ser de un mínimo de 3 meses y un máximo de 3 años. Pasado este período sólo se podrá seguir prorrogando

32. FEACEM. Información ofrecida por Pepa Torres, gerente de FEACEM (2017), en el seminario sobre CEE del módulo Entidades de acción social y voluntariado, del Máster de Economía Social y Cooperativas de la Universidad de Valencia, curso 2016/2017. 
el contrato hasta un máximo total de 6 años, si la empresa contratante acredita la contratación directa de personas sujetas al enclave (mínimo 1 persona para el caso de enclaves que ocupen hasta 20 trabajadores, y de 2 personas cuando ocupen a más de 20 trabajadores).

El enclave se realiza a partir de un contrato entre una empresa del mercado ordinario de trabajo y un CEE (entidad con un mínimo de un 70\% de personas contratadas con discapacidad), para la realización de obras y servicios que guarden una relación directa con la actividad normal de la empresa y que llevará a cabo un grupo de trabajadores/as con discapacidad del CEE. Existe un condicionante, y es que un mínimo del $60 \%$ del grupo de trabajo normal contemplado por el enclave debe estar formado por personas en riesgo de exclusión social (enfermedad mental, discapacidad física con grado mínimo de un 65\%, discapacidad intelectual mínima de un $33 \%$, parálisis cerebral, etc.), mientras que el $40 \%$ restante debe estar formado por trabajadores con un mínimo del $33 \%$ de discapacidad.

Es una dificultad agravada por el hecho de que la persona con enfermedad mental que participe en el enclave debe tener al menos un grado de discapacidad reconocido del $65 \%$, mientras que para la persona con discapacidad intelectual, solo se exige el $33 \%$.

\section{Recapitulación}

En relación a las personas con enfermedad mental dentro de las diferentes modalidades de empleo para personas con discapacidad nos encontramos la necesidad de que se produzcan una serie de cambios estadísticos necesarios para obtener una mejor radiografía de empleo de las mismas junto a una serie de cambios normativos que favorezcan si situación con respecto al empleo, que nos atrevemos a proponer aquí:

- La estigmatización que acompaña a la enfermedad mental favorece que oculten habitualmente su condición de persona enferma en el ámbito de la empresa privada, imposibilitando en estos casos el hecho de que la persona y la propia empresa pueda acogerse a beneficios fiscales o apoyos adaptados a su necesidad concreta.

- Siendo el empleo con apoyo, como hemos señalado, una vía óptima para el acceso al empleo ordinario de las personas con enfermedad mental, incidir en el mismo con incentivos específicos a las empresas junto a una preparación específica en materia de enfermedad mental de los preparadores laborales, sería una de las claves para mejorar los datos de inclusión laboral en empleo ordinario. La experiencia de las empresas de inserción con el acompañamiento desde el puesto 
de trabajo, en una función en cierto modo semejante a la de los preparadores laborales, puede ser un modelo de contraste y profesionalización en el apoyo a la mejora de la empleabilidad y la inclusión (Marhuenda, Martínez-Rueda, Galarreta y Arostegui, 2020; Chisvert-Tarazona, Palomares-Montero, Hernáiz-Agreda y Salinas, 2018).

- En cuanto al empleo público, si bien la oferta de la cuota de reserva para personas con discapacidad es mayor con respecto a la empresa privada, en el caso concreto de las personas con enfermedad mental conviene establecer cuotas específicas de reserva de empleo público, tal y como se ha comenzado a hacer en Andalucía.

- El trabajo por cuenta propia tiene una baja incidencia en cuanto a volumen y cifras en el caso de las personas con enfermedad mental. Siguiendo las recomendaciones del Plan de Acción de la Estrategia Española de Discapacidad 2014-2020, se propone que esta modalidad sea subvencionada de manera indefinida con el objetivo de incentivar el acceso a la misma.

- En relación a los CEE, tal y como se ha mostrado en el análisis de las distintas bases de datos, la falta de datos desagregados impide la implementación de ajustes más específicos para las personas con enfermedad mental. La posibilidad de datos desagregados por discapacidades es factible y relativamente sencilla tabulando los datos de los TC2 sobre el tipo de discapacidad que los CEE entregan en sus memorias justificativas anuales.

- Con respecto a los enclaves laborales y teniendo en cuenta que las personas con enfermedad mental son consideradas personas con especiales dificultades para la integración del mismo modo que lo son las personas con discapacidad intelectual; es necesario que la exigencia del $65 \%$ de discapacidad reconocida en las personas con enfermedad mental baje al 33\%, tal y como ocurre con las personas con discapacidad intelectual. 
(pp. 273-311)

\section{Bibliografía}

ÁLVAREZ, M.L.: "El acceso al empleo de personas con trastorno mental severo como proceso intersectorial. una visión desde Andalucía", Actas II Congreso de Rehabilitación en Salud Mental II Congreso Ibérico de Saúde Mental, 2003, Salamanca. Disponible en https://sid-inico.usal.es/documentacion/el-acceso-al-empleo-de-personas-con-trastorno-mental-severo-como-proceso-intersectorial-una-vision-desde-andalucia-ponencia/. (Extraído el 06/06/2020).

BECERRA TRAVER, M., MONTANERO FERNÁNDEZ, M. \& LUCERO FUSTES, M.: "Empleo normalizado con apoyo. Investigación de diferentes recursos de apoyo natural a trabajadores con discapacidad intelectual en tareas laborales que requieren autorregulación”, Futuex, 2012. Disponible en

http://riberdis.cedd.net/handle/11181/3417. (Extraído el 02/02/2020).

BOND, G.R., EVANS, L., SALYERS, M.P. et al.: "Measurement of Fidelity in Psychiatric Rehabilitation”, Ment Health Serv. Res., 2, 2000, pp. 75-87. Disponible en https://doi.org/10.1023/A:1010153020697. (Extraído el 10/10/2019).

CALVO GALLEGO, F.J.: "Los trabajadores autónomos dependientes: una primera aproximación”, Temas Laborales, $\mathrm{n}^{\circ} .81,2005$. Disponible en

https://www.juntadeandalucia.es/export/drupaljda/Temas\%20laborales $\% 20$ n\%2081.pdf. (Extraído el 10/02/2020).

CONFEDERACIÓN DE SALUD MENTAL DE ESPAÑA: "Informe sobre el estado de los derechos humanos de las personas con trastorno mental en España 2017”, 2018. Disponible en http://riberdis.cedd.net/handle/11181/5202 . (Extraído el 03/06/2020).

CHISVERT TARAZONA, M.J., PALOMARES MONTERO, D., HERNAIZ AGREDA, N. \& SALINAS, M.: "Trayectorias de aprendizaje en contextos informales. El caso de tres empresas de inserción”, CIRIEC-España, Revista de Economía Pública, Social y Cooperativa, 94, 2018, 185-216.

DOI: 10.7203/CIRIEC-E.94.12695

DE URRÍES, F.D.B.J., VERDUGO, M.A. \& PULIDO, R.F.: "Estándares de Calidad EUSE y Resultados en Empleo con Apoyo. Prácticas Basadas en la Evidencia”, 2012. Disponible en https://sid-inico.usal.es/documentacion/estandares-de-calidad-euse-y-resultados-en-empleo-con-apoyo-practicas-basadas-en-la-evidencia-ponencia/ (Extraído el 10/02/2020). 
FERNÁNDEZ GARCÍA, A.: "Crisis económica y medidas de fomento del empleo de las personas con discapacidad”, IUS Labor. Revista d'anàlisi de Dret del Treball, [en línea], n. ${ }^{\circ}$ 1, 2016. https://doi.org/307082 (Extraído el 08/06/2020).

GARCÍA, A.F. "Crisis económica y medidas de fomento del empleo de las personas con discapacidad”, IusLabor, (1). 2016.

DOI: http://dx.doi.org/307082 . (Extraído el 01/06/2020).

GARCÍA, A.B.: "Centros Especiales de Empleo de Iniciativa Social. Avances legislativos y ajustes necesarios", CIRIEC-España, Revista Jurídica de Economía Social y Cooperativa, no 35, Diciembre 2019, pp 95-123.

Disponible en http://ciriec-revistajuridica.es (Extraído el 20/02/2020).

JIMÉNEZ LARA, A.: "Informe Olivenza 2019, sobre la situación de la discapacidad en España”, 2019. Disponible en https://www.observatoriodeladiscapacidad. info/informe-olivenza-2019-sobre-la-situacion-general-de-la-discapacidad-en-espana/ (Extraído el 01/06/2020).

JORDÁN DE URRÍES, F.B. \& VERDUGO, M.A.: El empleo con apoyo en España. Análisis de variables que determinan la obtención y mejora de resultados en el desarrollo de servicios, Madrid: Real Patronato sobre Discapacidad, 2003

Disponible en: https://dialnet.unirioja.es/servlet/tesis?codigo=220887. (Extraído el 04/02/2020).

MARHUENDA, F., MARTÍNEZ-RUEDA, N., ARÓSTEGUI, I. \& GALARRETA, J.: "Nudos en el acompañamiento y la formación en las Empresas de Inserción: Agenda de temas pendientes", CIRIEC-España, Revista de Economía Pública, Socialy Cooperativa, 98, 2020, 247-285. DOI: 107203/CIRIEC-E.98.16124.

MIGLIORE A.: "Shelthered Workshops". En International Encyclopedia of Rehablititation, (Eds. STONE, J.H. \& BLOUIN, M.), 2010. Disponible en http://cirrie. buffalo.edu/encyclopedia/en/article/136/\#article . (Extraído el 06/02/2020).

MINISTERIO DE TRABAJO Y ASUNTOS SOCIALES \& UNIVERSIDAD CARLOS III DE MADRID: La cuota de reserva del 2\% del empleo para personas con discapacidad y la aplicación de medidas alternativas en empresas con más de 50 trabajadores: Un estudio sobre su cumplimiento en el contexto de las politicas de fomento del empleo, 2007. Disponible en http://sid.usal.es/idocs/F8/FDO22137/ cuotareserva_empleo_pcd.pdf. (Extraído el 17/02/2020).

OBSERVATORIO DE LAS OCUPACIONES - SEPE: Informe del Mercado de Trabajo de las Personas con Discapacidad, 2019. Disponible en: chrome-extension://oemmndcbldboiebfnladdacbdfmadadm/http:/www.sepe.es/contenidos/ observatorio/mercado_trabajo/3206-1.pdf (Extraído el 12/02/2020). 
ODISMET: Informe 4 del Observatorio sobre Discapacidad y Mercado de Trabajo ODISMET, 2019. Disponible en https://www.odismet.es/informes-publicaciones (Extraído el 12/02/2020).

ODISMET: Informe 1.09. Volumen de contratos especificos realizados a personas con discapacidad (ODISMET). Disponible en URL:

https://www.odismet.es/banco-de-datos/1 integracion-laboral-y-tendencias-delmercado-de-trabajo (Extraído el 01/06/2020).

OBSERVATORIO ESTATAL DE LA DISCAPACIDAD: Realidad, situación, dimensión y tendencias del empleo con apoyo en España y en el horizonte del año 2020, 2017. Disponible en

http://riberdis.cedd.net/handle/11181/5416 (Extraído el 05/06/2020).

PORTERO, I.B. \& ANEIROS, A.R. "Las personas con discapacidad ante la Unión Europea: del paternalismo inicial al reconocimiento de derechos", Los Tratados de Roma en su cincuenta aniversario: perspectivas desde la Asociación Española de Profesores de Derecho Internacional y Relaciones Internacionales, Marcial Pons, 2008, pp. 205-230. Disponible en: https://www.academia.edu/33797411/_Las_personas_ con_discapacidad_ante_la_Uni\%C3\%B3n_Europea_del_paternalismo_inicial_ al_reconocimiento_de_derechos_2007 (Extraído el 20/02/2020).

PULIDO, F.R., DIAZ, M.R. \& RAMÍREZ, M.G.: "La integración laboral de las personas con trastorno mental grave. Una cuestión pendiente", Psiquis, 25(6), 2004, pp. 264-281. Disponible en https://dialnet.unirioja.es/servlet/articulo?codigo=1069299 (Extraído el 20/01/2020).

RODRÍGUEZ V. \& CUETO B.: "El Trabajo de las Personas con discapacidad ante la crisis", Revista Internacional de Organizaciones, no 11, desembre 2013, pp. 61-86. Disponible en https://doi.org/10.17345/rio11.61-86 (Extraído el 03/02/2020). SENRA, J.M.S.C. \& VALDÉS, J.M.S.C.: Los enclaves laborales, Equalbur, 2004. Disponible en https://dialnet.unirioja.es/servlet/articulo?codigo=2248616 (Extraído 15/02/2020).

TEJEIRO, J.B., \& MONZÓN, J.L.: Economía social e inserción laboral de las personas con discapacidad en el País Vasco, 2008. Disponible en

https://www.fbbva.es/publicaciones/economia-social-e-insercion-laboral-de-laspersonas-con-discapacidad-en-el-pais-vasco/ (Extraído 03/02/2020).

VERDUGO, M.A. \& URRIES, B.J.: "Situación actual del empleo con apoyo en España”, Siglo Cero, 1998; 29(1): 23-31. Disponible en https://dialnet.unirioja. es/servlet/articulo?codigo=4528918 . (Extraído el 01/06/2020). 


\section{Normativa}

Ley 13/ 1982, de 7 de abril, de Integración Social de los Minusválidos (LISMI). BOE núm. 103, 30 de abril de 1982.

Ley 30/1984, de 2 de agosto, de medidas para la reforma de la Función Pública. BOE núm. 185, de 3 de agosto de 1984.

Ley 45/2002, de 12 de diciembre, de medidas urgentes para la reforma del sistema de protección por desempleo y mejora de la ocupabilidad. BOE núm. 298 de 13 de diciembre de 2002.

Ley 43/2006, de 29 de diciembre, para la mejora del crecimiento y del empleo. BOE núm. 312, de 30 de diciembre de 2006.

Ley 20/2007, de 11 de julio, del Estatuto del trabajo autónomo. BOE núm. 166, de $12 / 07 / 2007$.

Ley 26/2011, de 1 de agosto, de adaptación normativa a la Convención Internacional sobre los Derechos de las Personas con Discapacidad. Jefatura del Estado. BOE núm. 184, de 2 de agosto de 2011.

Ley 4/2017, de 25 de septiembre, de los Derechos y la Atención a las Personas con Discapacidad en Andalucía. BOJA no 191 de 04/10/2017

Ley 6/2017, de 24 de octubre, de Reformas Urgentes del Trabajo Autónomo. BOE núm. 257, de 25 de octubre de 2017.

Real Decreto Legislativo 1/2013, de 29 de noviembre, por el que se aprueba el Texto Refundido de la Ley General de derechos de las personas con discapacidad y de su inclusión social. BOE núm. 289, de 3 de diciembre de 2013.

Real Decreto 364/2005, de 8 de abril, por el que se regula el cumplimiento alternativo con carácter excepcional de la cuota de reserva en favor de los trabajadores con discapacidad. BOE núm. 94, 20 de abril 2005.

Real Decreto 2271/2004, de 3 de diciembre, por el que se regula el acceso al empleo público y la provisión de puestos de trabajo de las personas con discapacidad. BOE núm. 303, de 17 de diciembre de 2004.

Real Decreto 870/2007, de 2 de julio, por el que se regula el programa de empleo con apoyo como medida de fomento de empleo de personas con discapacidad en el mercado ordinario de trabajo. BOE núm.168, de 14 de julio de 2007. 